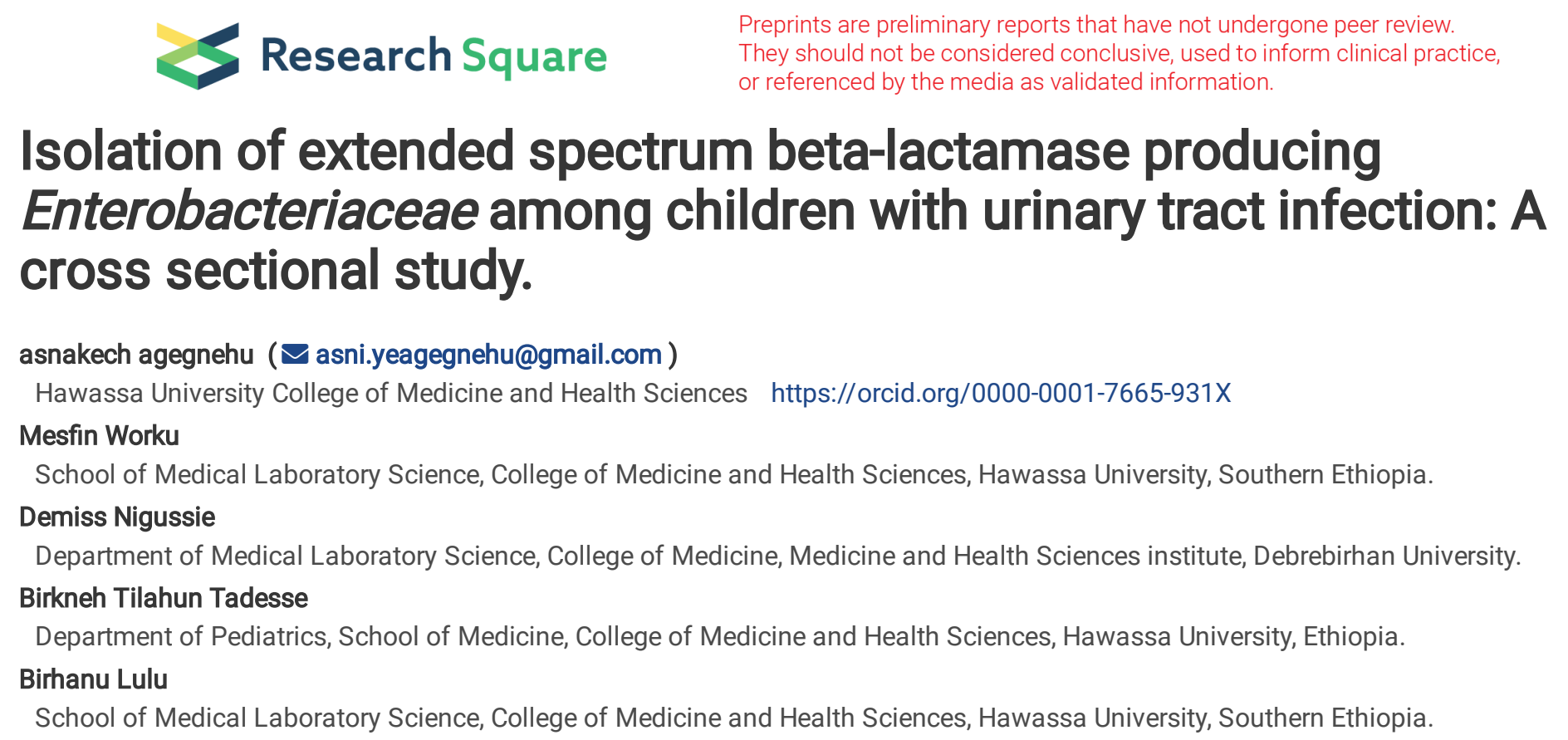

\section{Isolation of extended spectrum beta-lactamase producing Enterobacteriaceae among children with urinary tract infection: A cross sectional study.}

asnakech agegnehu ( $\sim$ asni.yeagegnehu@gmail.com )

Hawassa University College of Medicine and Health Sciences https://orcid.org/0000-0001-7665-931X

Mesfin Worku

School of Medical Laboratory Science, College of Medicine and Health Sciences, Hawassa University, Southern Ethiopia.

Demiss Nigussie

Department of Medical Laboratory Science, College of Medicine, Medicine and Health Sciences institute, Debrebirhan University.

Birkneh Tilahun Tadesse

Department of Pediatrics, School of Medicine, College of Medicine and Health Sciences, Hawassa University, Ethiopia.

Birhanu Lulu

School of Medical Laboratory Science, College of Medicine and Health Sciences, Hawassa University, Southern Ethiopia.

\title{
Research
}

Keywords: ESBL, Antimicrobial Resistance, UTI, Children

Posted Date: January 15th, 2020

DOI: https://doi.org/10.21203/rs.2.20886/v1

License: (-) (i) This work is licensed under a Creative Commons Attribution 4.0 International License. Read Full License 


\section{Abstract}

Background: Resistance of Gram-negative bacteria to antibiotics had increased at an alarming pace over the last two decades. Empirical antibiotic treatment of UTI practice created opportunity for frequent use of antibiotics that resulted in emergence of resistant strains. Extended spectrum beta-lactamase producing Enterobacteriaceae are emerging worldwide and are usually multi-drug resistant; thus, limiting treatment options for these organisms. Hence, it is mandatory to scrutinize the extent of the problem in the study area. Objective: We investigated the prevalence and correlates of extended spectrum beta-lactamase producing Enterobacteriaceae and their antibacterial resistance profile among children with urinary tract infection (UTI) at Hawassa University Comprehensive Specialized Hospital. Method: A hospital-based cross sectional study was conducted from February 1-July 30/ 2018. A semi-structured questionnaire was used to collect data from 284 children suspected of UTI. Bacterial species were isolated using standard bacteriological techniques. Antibiotic susceptibility testing was done using Kirby-Bauer disk diffusion method and ESBL production was detected by double disc synergy test. Data entry, cleaning and statistical analysis was done using SPSS version 20.

Results: Overall, Enterobacteriaceae accounted for 75\% (72/96) of UTI infections. The most frequent Enterobacteriaceae were E. coli , 44.4\% (32/72) and K. pneumoniae, 27.8\% (20/72). Overall, ESBL-producers within Enterobacteriaceae accounted for 41.7\% (30/72) and magnitude of multi-drug resistance level was $86.1 \%$ (62/72). ESBL producing K. pneumoniae and E. coli accounted for $70 \%(14 / 20)$ and $37.5 \%$ (12/32), respectively of all the respective isolates. Previous UTI within the past 12 month (AOR $=0.08,95 \% \mathrm{Cl}(0.01-0.57)$ and medium family wealth index $(\mathrm{AOR}=0.03,95 \% \mathrm{Cl}(0.00-0.27)$ were associated with infection of ESBL-producing Enterobacteriaceae .

Conclusion: ESBL producing Enterobacteriaceae were prevalent among UTI cases; where E. coli and K. pneumoniae were the major isolated resistant strains that contributed mainly to the problem. Majority of Enterobacteriaceae isolated were resistant to commonly prescribed drugs. Key words : ESBL, Antimicrobial Resistance, UTI, Children.

\section{Introduction}

Gram negative bacteria, especially the family Enterobacteriaceae are the common causes of both community and hospital acquired urinary tract infection (UTI). UTI ranks second next to upper respiratory tract infection where Escherichia coli (E. coli) and Klebsiella species are the most common pathogens [1, 2].

Over the past two decades, there has been wide use of extended broad- spectrum antibiotics to counter the increasing rates of ESBLproducing bacteria in patients with UTI [3]. ESBL-producing bacteria have been described as a pandemic [4]. Usually initial antibiotic treatment for UTI is empirical until the culture and sensitivity results are obtained. The improper and frequent use of antibiotics resulted in emergence of resistant strains. Resistance of Gram-negative bacteria to antibiotics had increased at an alarming pace over the last two decades [1]. Extended-Spectrum Beta-Lactamase (ESBL) producing bacteria, mostly E. coli and Klebsiella species are complicating treatment of UTI worldwide [5].

The resistance of Gram-negative bacteria is usually due to plasmid-mediated enzymes called ESBLs [6]. Bacterial resistance to $\beta$-lactam antibiotics occurs by three mechanisms: failure of the $\beta$-lactam to reach the penicillin-binding proteins (PBPs), low binding affinity to the PBPs and inactivation of the drug by $\beta$-lactamases. Among these $\beta$-Lactamases are the commonest cause of bacterial resistance to $\beta$ lactam antimicrobials [7].

$\beta$-lactamases are bacterial enzyme that inactivate $\beta$-lactam ring containing antibiotics. ESBLs are $\beta$-lactamases containing serine in their active site and are capable of hydrolyzing penicillin group of antibiotics, broad- and extended-spectrum cephalosporins, monobactam, and aztreonam, thereby causing resistance to them. However, they do not hydrolyze cephamycin antibiotics such as cefoxitin and cefotetan. They are generally inactive against the carbapenem antibiotics such as imipenem, meropenem, and ertapenem. Currently, carbapenems are regarded as the drugs of choice for treatment of infections caused by ESBL-producing organisms [8].

Antimicrobial resistance (AMR) in healthcare facilities is a global public health problem. Worldwide, the increasing rate of antibiotic resistance over time is leading to serious difficulty of antimicrobial treatment [9]. Although AMR is a global problem, the impact is higher in Sub-Saharan Africa (SSA) due to limited available resources for healthcare infrastructure and wide irrational use of antimicrobial agents. Of all those who take antibiotic, more than one-third do not get prescriptions from a doctor, and about a quarter obtain antibiotics from an informal dispenser $[7,10]$.

The risk of ESBL-producing Enterobacteriaceae was investigated in different part of the nation on clinical samples. The extent of these problems was not investigated in the study area previously. The study tried to explore prevalence and antimicrobial resistance profile of

Page $2 / 13$ 
ESBL-producing Enterobacteriaceae isolated from UTI suspected children. Findings of the study will help improve local empiric drug choice for the treatment of UTI in children.

\section{Methods And Material Study area, design \& period}

Hawassa University College of Medicine and Health Sciences Comprehensive Specialized Hospital is a tertiary level teaching hospital found in Hawassa city, Southern Ethiopia. Hawassa is the capital city of Southern Nations Nationalities and Peoples Regional State (SNNPRs) and is located $273 \mathrm{~km}$ to South of Addis Ababa. HUCSH has an estimated catchment of more than 5 million. According to information from hospital HMIS unit, the pediatric outpatient department (OPD) receives about 9,000 cases annually. The Pediatric Department of HUCSH has a total of 65 beds with average monthly admission rate of 75 children. We employed a cross sectional study design from February 1/ 2018 to July 30/ 2018 to enroll children with suspected UTI at the Pediatrics Department of HUCSH.

\section{Study Participants}

Children below the age of 15 years who were clinically suspected to have UTI and presenting to Hawassa University Comprehensive Specialized Hospital (HUCSH) were enrolled. Written informed assent was obtained from guardians or patients before data collection.

\section{Inclusion criteria:}

Patients who had at least one of the signs and symptoms of urinary tract infection like; frequency, urgency, dysuria, abdominal pain, back pain, fever $\left(>38.0^{\circ} \mathrm{C}\right)$.

\section{Exclusion criteria:}

Patients who received antibiotics within two weeks before presentation to the hospital were excluded.

\section{Sample size determination and Sampling techniques}

Sample size calculated using single-population proportion formulae with assumptions based on a previous study done at Tikur Anbessa Specialized Hospital, which showed prevalence of extended spectrum $\beta$-lactamase (ESBL) of 78.6\% [8] gave the largest sample size. The final sample size for a population survey considering a $10 \%$ non-response rate gave 284 subjects suspected of UTI.

\section{Formulae: (Sample size) $n=Z^{2} a / 2 p(1-p) / d^{2}$}

Where: $\mathrm{n}=$ the number of study subjects from which samples will be taken

$\mathrm{P}=$ anticipated population proportion. Prevalence of ESBL taken as 0.786

$\mathrm{Z}=$ Standard normal distribution value at $95 \% \mathrm{Cl}$, which is 1.96

$d=$ Degree of precision taken as $5 \%$.

\section{Data Collection}

\section{Socio-demographic and clinical data:}

Socio-demographic characteristics like; age, sex, residence, paternal and maternal educational and occupational status, family living standard and clinical history of participants such as hospital admission and history of UTI within the past 12 months were recorded.

\section{Laboratory data collection:}

A total of 284 early morning mid-stream (MSU) and catheterized urine samples was collected using sterile, clean, transparent, screwcapped, wide-mouth plastic cups. All urine samples were properly labeled with unique code, age, sex, and time of collection and the sample was transported to microbiology laboratory within two hours of collection. By using the standard wire loop which has $1 \mu l$ 
diameter approximately $0.001 \mathrm{ml}$ urine was inoculated on 5\% sheep Blood agar (OXOID Ltd. England) and MacConkey agar (OXOID Ltd., Basingstoke, United Kingdom) plate and the plates were incubated aerobically at $37^{\circ} \mathrm{C}$ for $24 \mathrm{hrs}$.

A significant bacterium was determined on Blood agar plate (BAP) if single midstream and catheterized urine culture yields at least $10^{5}$ $\mathrm{CFU} / \mathrm{mL}$ [9]. All types of colonies on the primary plates were examined macroscopically for hemolysis, changes in physical appearance of differential media, and the colony characteristics were recorded.

Morphology, Gram reaction and arrangement of the microorganisms were noted to identify the bacteria by Gram's staining method. Biochemical tests were used for further identifications of Enterobacteriaceae isolates like Indole production, sugar fermentation, $\mathrm{H}_{2} \mathrm{~S}$ and gas production, citrate utilization, motility test, mannitol test, and urease and oxidase test. In case of delay, the isolated bacteria were kept at $2-8^{\circ} \mathrm{C}$ in the nutrient broth for not more than $24 \mathrm{hrs}$ until the antimicrobial sensitivity test was done.

\section{Detection of ESBL producing Enterobacteriaceae}

ESBL production of Enterobacteriaceae were first screened by the standard disk diffusion

method and then were confirmed by using the double disc diffusion method as set by Clinical and Laboratory Standards Institute guideline (CLSI) [10].

\section{Screening test for ESBL producing Enterobacteriaceae}

Screening test for ESBL detection was done according to the CLSI guidelines [10]. A 0.5 McFarland's standard suspension of the test isolates was streaked by using a sterile cotton swab on the surface of a Muller Hinton Agar plates (MHA) (OXOID Ltd. England). Cefotaxime (CTX: $30 \mu \mathrm{g})$, ceftazidime (CAZ: $30 \mu \mathrm{g}$ ) and ceftriaxone (CTR: $30 \mu \mathrm{g}$ ) were placed on the MHA using an automated dispenser and lightly pressed on to make sure they are firmly placed to the media. These plates were incubated for $18-24$ hours at $37^{\circ} \mathrm{C}$. Isolates showing inhibition zone size below the CLSI stated break points were considered a potential ESBL-producer when the inhibition zone size for: ceftazidime $<22 \mathrm{~mm}$, cefotaxime $<27 \mathrm{~mm}$ and ceftriaxone $<25 \mathrm{~mm}$.

Confirmatory test for ESBL producing Enterobacteriaceae: The ESBLs detection was carried out by double disc synergy test using third generation cephalosporins and modified double disc synergy test using cefepime along with the third generation cephalosporins. All the strains which were positive for ESBL screening test was selected for checking for ESBLs production.

\section{Double disk synergy test (DDST).}

The double disc synergy test (DDST) is used as primary isolation method to identify the ESBL producing organisms. Antibiotic discs of amoxicillin / clavulanic acid $(20 / 10 \mu \mathrm{g})$ at the center; cefotaxime $(30 \mu \mathrm{g})$ and ceftazidime were placed at a distance of $15 \mathrm{~mm}$ apart center to center and incubated at $37^{\circ} \mathrm{C}$ for $18-24$ hours. A clear extension of cefotaxime and ceftazidime inhibition zones towards the disc containing clavulanic acid was considered as ESBL producer. Isolates which were screened and found positive for ESBL production may be negative for confirmatory test using DDST due to the coproduction of other beta lactamases like AMPC lactamase. In such cases, modified double disk synergy test were used using Cefepime antibiotics for inhibiting other beta lactamases (AMPC lactamase).

\section{Modified Double disk synergy test (MDDST).}

The test is performed by using a disc of amoxicillin-clavulanate $(20 / 10 \mu \mathrm{g})$ along with four cephalosporins (cefotaxime, ceftriaxone, ceftazidime and cefepime). A disc which contained amoxicillin clavulanate $(20 / 10 \mu \mathrm{g})$ was placed in the centre of the plate. The discs of third generation cephalosporin (cefotaxime, ceftriaxone and ceftazidime) and fourth generation cephalosporin (cefepime) were placed 15 $\mathrm{mm}$ and $20 \mathrm{~mm}$ apart respectively, centre to centre to that of the amoxicillin clavulanate disc on the surface of MHA plate, as recommend by $\mathrm{CLSI}, 2017$. The plates were incubated at $37^{\circ} \mathrm{C}$ for 24 hours. Any distortion or increases in the zone toward the disc of amoxicillinclavulanate were considered as positive for ESBLs production.

\section{Antimicrobial Susceptibility Testing}

Antibiotic susceptibility testing was done by Kirby Bauer disk diffusion method on MHA as recommended by the CLSI guidelines $[9,10]$ for the following antimicrobial discs: ampicillin (AMP: $10 \mu \mathrm{g}$ ), amoxicillin-clavulanic acid (AMC: 20/10 $\mu \mathrm{g}$ ), ciprofloxacin (CEP: $30 \mu \mathrm{g}$ ), gentamicin (G: $10 \mu \mathrm{g})$, trimethoprim sulfamethoxazole (STX: 1.25/23.75 $\mu \mathrm{g})$ cefotaxime (CTX: $30 \mu \mathrm{g})$, ceftriaxone (CTR: $30 \mu \mathrm{g})$, cefoxitin 
(FOR: $30 \mu \mathrm{g}$ ), tetracycline (TE: $30 \mu \mathrm{g}$ ), nitrofurantoin (NIF: $300 \mu \mathrm{g}, \mathrm{BD}$ ), norfloxacin (NOR: $10 \mu \mathrm{g})$, and meropenem (MEM: $10 \mu \mathrm{g})$. The selections of antimicrobial agents for Enterobacteriaceae depend on the availability and recommendations from CLSI 2017. After overnight incubation of the Mueller-Hinton agar plate with antimicrobial discs at $37^{\circ} \mathrm{C}$, the zone of inhibition was measured by using a ruler and interpreted by comparing the Kirby-Bauer chart. The antibiotic discs used were from Abtek Biologicals Ltd., Liverpool, United Kingdom product. Control strain ATCC-25922 E. coli used to monitor quality of antibiotic discs during antimicrobial susceptibility testing. During ESBL detection methods, E. coli ATCC 25922 (ESBL negative) and K. pneumoniae ATCC 700603 (ESBL positive) were used. Multidrug resistance was defined as simultaneous non-susceptible to three or more drugs from different classes of antibiotics.

\section{Data Analysis}

The data were analyzed by using SPSS version 20 software. All variables with a P-value $<0.25$ in bivariate analysis were taken to multivariable logistic regression analysis. On multivariable analysis, variables with P-value $<0.05$ at $95 \%$ confidence interval were considered as statistically significant. Wealth status of the family used as a variables using principal component analysis (PCA).

\section{Ethical Considerations}

Written informed assent were obtained from study participants or caretakers of children. Patient privacy was protected by de-identification of records. Names of patients were coded. All data obtained in the course of the study were kept confidential, and was used solely for the purpose of the study. Positive laboratory result from the study participant was communicated to their physicians for appropriate treatment or management.

\section{Results}

\section{Demographic and clinical characteristics}

A total of 284 children with age range $0-14$ years, suspected of UTIs were included in the study. Of the total study participants, $52.46 \%$ were male (149/284), 61.3\% (174/284) were living in urban, 52.8\% (150/284) were from inpatient, $20.1 \%(57 / 284)$ were malnourished, $11.7 \%$ (34/284) were surgery exposure within the past 6 month, hospital admission and history of UTI within the past 12 month accounted $33.8 \%(96 / 284)$ and $14.1 \%(40 / 284)$ respectively (Table 1$)$.

\section{Frequency of Enterobacteriaceae Isolates}

From 284 urine specimens, 90 of the samples were culture positive and a total of $96(33.8 \%)$ bacterial species were identified. Among these, $75 \%$ (72/96) were Enterobacteriaceae with E. coli $(44.4 \%, n=32 / 72)$, K. pneumoniae $(27.8 \%, n=20 / 72)$, Klebsiella oxytoca (8.33\%, $n=6 / 72)$, Providencia spp. $(5.6 \%, n=4 / 72)$, Citrobacter diversus $(4.16 \%, n=3 / 72)$, Enterobacter cloacae $(2.8 \%, n=2 / 72)$, Proteus mirabilis $(2.8 \%, n=2 / 72), K$. ozaenae $(4.16 \%, n=3 / 72)$ being most common isolates. The remaining $25 \%(24 / 96)$ from the non Enterobacteriaceae group were Pseudomonas spp. (3.12\%, $n=3 / 96)$, Enterococcus spp. $(11.5 \%, n=11 / 96)$, S. aures $(5.21 \%, n=5 / 96)$, S. saprophyticus (3.12\%, $\mathrm{n}=3 / 96)$ and yeast cell $(2.1 \%, \mathrm{n}=2 / 96)$ (Table 2$)$.

\section{Prevalence of ESBL-producing Enterobacteriaceae}

Enterobacteriaceae were slightly higher among female study subjects $(55.6 \%, \mathrm{n}=40 / 72)$ than their male counter parts $(41.7 \%, \mathrm{n}=30 / 72)$. More than half of Enterobacteriaceae were isolated from study subjects who attended inpatient department (59.7\%, 43/72), urban (58.3\%, $42 / 72)$ and aged less than four years $(54.2 \%, 39 / 72)$. Potentially ESBL producer Enterobacteriaceae accounted for $58.3 \%(42 / 72)$ of the total isolated while 71.4\% (30/42) were confirmed as ESBL producers. The proportion of ESBL producer bacteria within Enterobacteriaceae was 41.7\% (30/72). Klebsiella species 25\% (18/72) and E. coli 16.7\% (12/72) were the most frequently isolated Enterobacteriaceae (Table 2), (Figure 1).

\section{Factors associated to ESBL producing Enterobacteriaceae}


During bivariate analysis paternal occupation, maternal education, paternal education, age, place of residence, patient type, history of UTI within the past 12 month, and family wealth index were eligible for multivariable analysis $(P<0.25)$. Children with a history of UTI within the past 12 months were less likely to be infected with ESBL producing Enterobacteriaceae as compared to those with no UTI (AOR= 0.076 with $95 \% \mathrm{Cl}(0.010-0.569)$. Family wealth index of medium were less likely to be infected with ESBL producing Enterobacteriaceae as compared to those with poor family wealth index (AOR $=0.029$ with $95 \% \mathrm{Cl}(0.003-0.265)$ (Table 3).

\section{Antibiotic resistance profile of isolated Enterobacteriaceae}

The antibiotics resistance profile of Enterobacteriaceae isolated in urine specimen against 12 antibiotics is presented in Table 6. Regarding antibiotic susceptibility test, total isolated Enterobacteriaceae had varied non-susceptible result to selected antibacterial drugs: ampicillin (95.8\%), amoxicillin/clavulanic acid (94.4\%), trimethoprim-sulfamethoxazole (86.1\%), gentamycin (86.1\%), ciprofloxacin (47.2\%), Norfloxacin (45.8\%), meropenem (40.3\%) and nitrofurantoin (26.4\%). During antibiotic susceptibility testing the results of intermediate were included in the resistance for purpose of analysis.

The drug resistance profiles of E. coli to different selected antibacterial drug also indicated varied results: ampicillin (90.6\%), amoxicillin/clavulanic acid (93.8\%), trimethoprim-sulfamethoxazole (90.6\%), gentamycin (87.5\%), meropenem (18.8\%) and nitrofurantoin (15.6\%). In K. pneumoniae different resistance was observed against ampicillin (95\%), amoxicillin/clavulanic acid (95\%), gentamycin (85\%), ceftriaxone (85\%), tetracycline (85\%), trimethoprim-sulfamethoxazole (85\%), nitrofurantoin (35\%) and ciprofloxacin (35\%) (Table 4).

Out of the 72 Enterobacteriaceae isolates tested for antibiotic susceptibility testing, 62 (86.1\%) of them proved non-susceptible to three or more drugs belonging to different antibiotics classes. Four (5.6\%) of the isolates had shown non-susceptible to all antibiotic drugs tested. Among the total ESBL-producing Enterobacteriaceae, 96.7\% were multi-drug resistance (Table 5).

\section{Drug resistance of ESBL-producing Enterobacteriaceae}

Almost all ESBL-producing Enterobacteriaceae were resistant to Amoxacillin/Clavulanic acid (96.7\%). They are also resistant to ampicillin (96.7\%), trimethoprim-sulfamethoxazole (96.7\%), gentamycin (96.7\%), cefotaxime $(96.7 \%)$, ceftriaxone $(90 \%)$ and tetracycline $(86.7 \%)$ as compared to ESBL non-producers (Table 6).

\section{Discussion}

In this study; 284 urine samples were collected from study participants. Among these; 90 of the samples were culture positive and a total of 96 bacterial species were isolated. Gram negative bacteria $(78.1 \%, n=75 / 96)$ dominated over the Gram positive bacteria. Finding of this study was comparable to study conducted at Tikur Anbessa Specialized Hospital on (Gram negative organisms (74.5\%) [8]. In our study, prevalence of urinary tract infection among study subjects was $33.8 \%(96 / 284)$. This study had high prevalence compared to studies conducted at Dessie (22.7\%) [11], Rwanda (19.3\%) [12], and Nigeria (17.6\%) [13]

Prevalence of ESBLs producers within the Enterobacteriaceae in the study was $41.7 \%$. This finding is consistent with similar studies carried out at Jimma University Specialized Hospital (38.4\%) [14], in Addis Ababa (50.7\%) [15], in Nigeria (47.1\%) [16] and in India (38.2\%) [17].

The ESBLs prevalence rate in the present study was much lower than those reported from Tikur Anbessa Specialized Hospital (78.6\%) conducted variably on urinary and septicemia isolates [8]. The decline observed in our study might be attributed to the inclusion of only urine specimens; additionally, the high prevalence (78.6\%) might be because of small number of Enterobacteriaceae isolated compared to the current study. The ESBL prevalence was also lower than those reported in Burkina Faso 58\%, from clinical samples [18] and Nepal $62.31 \%$ from urinary isolates [19], these might be due to the inclusion of all age groups in the former study.

On the other hand, prevalence of ESBL observed in this study was higher than other studies conducted in Adama 25\% [20], Morocco $25.5 \%$ [21], Iran $28.4 \%$ [22] and Korea $16.7 \%$ [23], that could be attributed to variation in drug management policies, disparity in geographical variation and other local factors. The higher prevalence seen in our study compared to developed countries for example in Turkey (10.4\%) [24] might be explained by the fact that developed countries have strict infection control policies and practices, shorter average hospital stays, better nursing barriers that are known to substantially decrease the chances of acquisition and spread of ESBL producing strains. 
In this study Escherichia coli was the most common cause of UTI followed by K. pneumoniae, and this finding is in agreement with others finding elsewhere $[15,25,26]$. Even though E. coli had high isolation rate $(44.4 \%)$ in the study, Klebsiella spp. was identified as the major ESBL producer $25 \%$ (18/72) followed by E. coli $16.7 \%$ (12/72). When compared to other studies, higher prevalence was documented from Jimma University Specialized Hospital indicated that the magnitude of ESBL producer of $K$. pneumoniae (70.4\%) and E. coli (28.2\%) [14], Tikur Anbessa Specialized Hospital ESBL-E. coli (100\%) and ESBL-K. pneumoniae (84.2\%) [8] and Ziauddin University Hospital, Pakistan Klebsiella species (84.61\%) and Escherichia coli (68.55\%) [27]. The decline observed in our study can be attributed to percentage of ESBL production of individual bacterial calculated from total Enterobacteriaceae isolates.

In multivariable analysis; Previous UTI within the past 12 months and family wealth index were identified as associated factors for ESBL producing Enterobacteriaceae in this study. The same result was documented in a study done from Northwest Ethiopia [4]. However, additional factor like family wealth index were identified in this study, which were not indicated in the former study.

Among the total Enterobacteriaceae isolates, Multi-drug resistants' accounted for $86.1 \%$. This result is almost similar with a study done at Northwest Ethiopia where, MDRE was 87.4\% [4]. But when compared to other studies, current study revealed higher prevalence of MDRE; Addis Ababa, Ethiopia 68.3\% [15], Chicago, USA 76\% [28], Nepal 64.04\% [29] and Iran 52.7\% [26]. Multi-drug resistance ESBL-producing Enterobacteriaceae accounted $96.7 \%$, this result is directly in line with a study done at Addis Ababa, Ethiopia 96.3\% [15]. In our country drug resistance ESBL-producing Enterobacteriaceae were prevalent. Therefore, efforts should be made to follow strict infection control measure.

The total Enterobacteriaceae isolated was 75\% from the total bacteria identified. These Enterobacteriaceae showed different nonsusceptible result for commonly used drugs: Ampicillin (95.8\%), amoxicillin/clavulanic acid (94.4\%), trimethoprim-sulfamethoxazole (86.1\%), gentamycin (86.1\%), ciprofloxacin (47.2\%), Norfloxacin (45.8\%), Meropenem (40.3\%) and nitrofurantoin (26.4\%). The results of our study are in line with the findings of studies conducted in Iran (trimethoprim-sulfamethoxazole $93.6 \%$, Ciprofloxacin $40.4 \%$, tetracycline 84.5\%) [26] and in Bangladesh, 97.8\% for trimethoprim-sulfamethoxazole [30]. On the other hand, our finding were higher than the study done in Chicago, USA (ampicillin 55\%, amoxicillin/clavulanic acid 10\%, trimethoprim-sulfamethoxazole 24\%, nitrofurantoin 14\%) [28].

In the current study majority of ESBL producing Enterobacteriaceae were non-susceptible to commonly prescribed drugs: Gentamycin (96.7\%), trimethoprim-sulfamethoxazole (96.7\%), Ceftriaxone (90\%), Ampicillin (96.7\%), cefotaxime (96.7\%) and Amoxacillin/clavulanic acid (96.7\%). This result was comparable to study reported in India, which showed that for Gentamycin (83.3\%), trimethoprimsulfamethoxazole (89.7\%), Ceftriaxone (94.9\%), Ampicillin (96.1\%), cefotaxime (98.7\%) and Amoxacillin/clavulanic acid (98.7\%) [17]. and also comparable with study in Addis Ababa, Ethiopia (Amoxacillin/clavulanic acid 91.5\%, trimethoprim-sulfamethoxazole 89.8\%) [15]. This may suggest that the production of ESBLs by the family of Enterobacteriaceae may limit the treatment option available for the management of the infections caused by this group of bacteria. Thus the members of the family of Enterobacteriaceae that were proven to be produce ESBL pose a serious problem in the clinical management of UTI which trigger to put strong effort for the prevention of ESBL occurrence.

\section{Conclusion}

Our research finding evidenced that ESBL producing bacteria was prevalent among children with UTI. From the total bacteria species isolated, Enterobacteriaceae covered majority of the percent. Most of these Enterobacteriaceae were isolated from patients who attended inpatient department. Regarding ESBL producing specific bacteria species, ESBL producing Klebsiella species were the most frequent isolates followed by E. coli among Enterobacteriaceae. Majority of Enterobacteriaceae had resistance to commonly prescribed antibiotics. In the study, the most effective drug for ESBL producers and non-ESBL producers identified was nitrofurantoin.

\section{Limitations of the Study}

Certain clinical features such as ICU admission and circumcision (only for boy) did not assess as potential associated factor for ESBL production due to few numbers of cases. Molecular epidemiological study and characterization of ESBL types were not conducted.

\section{Declarations}

Data Availability

Page $7 / 13$ 
Raw data can be presented by the principal investigator upon reasonable request.

\section{Ethical Approval and consent to participate}

Ethical clearance was granted from Hawassa University College of Medicine and Health Sciences Institutional Review Board with a reference number IRB/156/10. Written informed assent was obtained from all study participant parents/guardians by telling them about the objective of the study before collecting the laboratory data. All data obtained in the course of the study were kept confidential, and was used solely for the purpose of the study. Moreover, all investigators were assured to guarantee safety and proper care of the study participants.

\section{Consent for publication}

Not applicable

\section{Competing Interest}

The authors declare that they have no competing interests.

\section{Authors' Contributions}

AA conceived the study; analyzed and interpreted the data; and prepared the manuscript draft. Dr. BTT guided the analysis, interpreted the data and helped in drafting the manuscript. MW and DN; conceived the study and helped during analysis and BL helped during analysis.

\section{Funding}

Hawassa University College of Medicine and Health Sciences: No role in the design of the study and collection, analysis, and interpretation of data and in writing the manuscript.

\section{Acknowledgments}

We would like to thank Hawassa University College of Medicine and Health Sciences for financial support. We also thank all the study participants and their parents/guardians.

\section{References}

1. Ali KE, Mohammed IA, Difabachew MN, Demeke DS, Haile T, ten Hove R-J, Kumssa TH, Woldu ZL, Haile EL, Tullu KD: Burden and genotype distribution of high-risk Human Papillomavirus infection and cervical cytology abnormalities at selected obstetrics and gynecology clinics of Addis Ababa, Ethiopia. BMC cancer 2019, 19(1):1-9.

2. Getahun F, Mazengia F, Abuhay M, Birhanu Z: Comprehensive knowledge about cervical cancer is low among women in Northwest Ethiopia. BMC cancer 2013, 13(1):2.

3. Garland SN, Johnson JA, Savard J, Gehrman P, Perlis M, Carlson L, Campbell T: Sleeping well with cancer: a systematic review of cognitive behavioral therapy for insomnia in cancer patients. Neuropsychiatric disease and treatment 2014, $10: 1113$.

4. Eshetie S, Unakal C, Gelaw A, Ayelign B, Endris M, Moges F: Multidrug resistant and carbapenemase producing Enterobacteriaceae among patients with urinary tract infection at referral Hospital, Northwest Ethiopia. Antimicrobial Resistance and Infection Control 2015, 4(12):DOI:10.1186/s13756-13015-10054-13757.

5. Chandra S: Extended-Spectrum Beta-Lactamase Infections. Curr Emerg Hosp Med Rep (2013), 1:145-148.

6. CDC: Antibiotic resistance threats in the United States In. U.S. department of health and human services: centers for disease control and prevention; 2013.

7. Mark E. Rupp, Paul D. Fey: Extended Spectrum $\beta$-Lactamase (ESBL)-Producing Enterobacteriaceae Considerations for Diagnosis, Prevention and Drug Treatment. Drugs 2003, 63(4):353-365.

8. Legese MH, Mulugeta G, Weldearegay, Asrat D: Extended-spectrum beta-lactamase- and carbapenemase-producing Enterobacteriaceae among Ethiopian children. Infection and Drug Resistance 2017, 10.

9. Cheesbrough M: District Laboratory Practice in Tropical Countries. Published in the United States of America by Cambridge University Press, New York; 2006. 
10. CLSI: Performance Standards for Antimicrobial Susceptibility Testing. In: $27^{\text {th }}$ edition, CLSI supplement M100. Wayne, PA: Clinical and Laboratory standards institute; 2017.

11. Abera B, Kibret M, Mulu W: Extended-Spectrum beta $(\beta)$-Lactamases and Antibiogram in Enterobacteriaceae from Clinical and Drinking Water Sources from Bahir Dar City, Ethiopia. PLOS ONE 2016.

12. Muvunyi CM, Masaisa F, Bayingana C, Mutesa L, Musemakweri A, Muhirwa G, Claeys GW: Decreased Susceptibility to Commonly Used Antimicrobial Agents in Bacterial Pathogens Isolated from Urinary Tract Infections in Rwanda: Need for New Antimicrobial Guidelines. Am J Trop Med Hyg 2011, 84(6):923-928.

13. Ogbukagu CM, Anakwenze VN, Ekwealor CC, Ezemba CC, Ekwealor IA: Incidence of Urinary Tract Infections (UTI) amongst Patients Attending Primary Health Centres in Anambra State. Advances in Microbiology 2016, 6:537-547.

14. Siraj SM, Ali S, Wondafrash B: Extended-spectrum $\beta$-lactamase production in Klebsiella pneumoniae and Escherichia coli at Jimma University Specialized Hospital, South-West, Ethiopia. Molecular Microbiology Research 2015, 5 (1):1-9.

15. Teklu DS, Negeri AA, Legese MH, Bedada TL, Woldemariam HK, Tullu KD: Extended-spectrum beta-lactamase production and multidrug resistance among Enterobacteriaceae isolated in Addis Ababa, Ethiopia. Antimicrobial Resistance and Infection Control 2019, 8(39):doi.org/10.1186/s13756-13019-10488-13754.

16. Azekhueme I, Moses AE, Abbey SD: Extended Spectrum Beta-Lactamases in Clinical Isolates of Escherichia coli and Klebsiella pneumoniae from University of Uyo Teaching Hospital, Uyo-Nigeria. Journal of Advances in Medical and Pharmaceutical Sciences 2015, 2(3):117-125.

17. SEGAR L, KUMAR S, JOSEPH NM, SIVARAMAN U: Prevalence of extended spectrum beta-lactamases among Enterobacteriaceae and their antibiogram pattern Asian Journal of Pharmaceutical and Clinical Research, 2015, 8(5):220-223.

18. Ouedraogo A-S, Sanou M, Kissou A, Sanou S, Solaré H, Kaboré F, Poda A, Aberkane S, Bouzinbi N, Sano3 I: High prevalence of extended-spectrum ß-lactamase producing enterobacteriaceae among clinical isolates in Burkina Faso. BMC Infectious Diseases 2016, 16(32).

19. Yadav K, Prakash S: Screening of ESBL Producing Multidrug Resistant E. coli from Urinary Tract Infection Suspected Cases in Southern Terai of Nepal. Journal of Infectious Diseases and Diagnosis 2017, 2(2):116.

20. Mulisa G, Selassie LG, Tilaye W, Jarso G, Shiferew T, Zewdu A, Abebe W, Belachew F, Sewunet T: Prevalence of Extended Spectrum Beta-lactamase Producing Enterobacteriaceae: A Cross Sectional Study at Adama Hospital, Adama, Ethiopia. Journal of Emerging Infectious Diseases 2015, 1(1):doi.org/10.4172/2472-4998.1000102.

21. Bouamria E, Arsalanea L, Kamounia YE, Zouhaira S: Antimicrobial susceptibility of urinary Klebsiella pneumoniae and the emergence of carbapenem-resistant strains: A retrospective study from a university hospital in Morocco, North Africa African Journal of Urology 2015, 21:36-40.

22. Khaledi A, Esmaeili D, Esmaeili K, Barzegar F, Ghamari N, Razipour H, Rostami H: Prevalence of Extended-Spectrum- $\beta$-Lactamaseproducing Escherichia coli isolates among uropathogensin a Pediatrics Hospital. Der Pharma Chemica 2016, 8(3):161-165.

23. Kima YH, Yanga EM, Kima CJ: Urinary tract infection caused by community-acquired extended-spectrum-lactamase-producing bacteria in infants[1]. journal of pediatric 2017, 93(3):260-266.

24. Dotis J, Printza N, Marneri A, Gidaris D, Papachristou F: Urinary tract infections caused by extended-spectrum beta-lactamaseproducing bacteria in children: a matched case-control study. The Turkish Journal of Pediatrics 2013, 55:571-574.

25. Beyene G, Tsegaye W: bacterial uropathogens in urinary tract infection and antibiotic susceptibility pattern in Jimma University Specialized Hospital, Southwest Ethiopia. Ethiopian Journal of Health Science July 2011, 21(2).

26. Shahla Mansouri SA: Prevalence of Multiple Drug Resistant Clinical Isolates of Extended-Spectrum Beta-Lactamase Producing Enterobacteriaceae in Southeast Iran. Iran journal of Medical Sciences 2010, 35(2):101-108.

27. Afridi FI, Farooqi BJ, Hussain A: Frequency of extended spectrum beta lactamase producing enterobacteriaceae among urinary pathogen isolates. Journal of the College of Physicians and Surgeons Pakistan 2011, 21(12):741-744.

28. Khawcharoenporn T, Vasoo S, Singh K: Urinary Tract Infections due to Multidrug-Resistant Enterobacteriaceae: Prevalence and Risk Factors in a Chicago Emergency Department. Hindawi Publishing Corporation Emergency Medicine International 2013:doi.org/10.1155/2013/258517.

29. Thakur S, Pokhrel N, Sharma M: Prevalence of Multidrug Resistant Enterobacteriaceae and Extended Spectrum $\beta$ Lactamase Producing Escherichia Coli in Urinary Tract Infection. Research Journal of Pharmaceutical, Biological and Chemical Sciences 2013, $4(2): 1615$. 
30. Akhtar N, Rahman R, Sultana S: Antimicrobial Sensitivity Pattern of Escherichia coli Causing Urinary Tract Infection in Bangladeshi Patients. American Journal of Microbiological Research 2016, 4(4):122-125.

\section{Tables}

Table 1: Demographic and clinical characteristics of study participants among UTI suspected children $(<15$ years) at HUCSH from Feb 1/ 2018-July 30, Hawassa, Ethiopia.

\begin{tabular}{|c|c|c|c|}
\hline \multicolumn{2}{|l|}{ Variables } & Numbers & Percentages \\
\hline \multirow[t]{3}{*}{ Age } & $0-4$ years & 165 & 56.9 \\
\hline & $5-9$ years & 59 & 20.3 \\
\hline & $10-14$ & 66 & 22.8 \\
\hline \multirow[t]{2}{*}{ Sex } & Male & 149 & 52.5 \\
\hline & Female & 135 & 47.5 \\
\hline \multirow[t]{2}{*}{ Place of residence } & Urban & 174 & 61.3 \\
\hline & Rural & 110 & 38.7 \\
\hline \multirow[t]{2}{*}{ Patient type } & Outpatient & 134 & 47.2 \\
\hline & Inpatient & 150 & 52.8 \\
\hline \multirow[t]{2}{*}{ Malnourished } & Yes & 57 & 20.1 \\
\hline & No & 227 & 79.9 \\
\hline \multirow[t]{2}{*}{ Hospital admission within the past 12 months } & Yes & 96 & 33.8 \\
\hline & No & 188 & 66.2 \\
\hline \multirow[t]{2}{*}{ Surgery within the past 6 month } & Yes & 34 & 11.7 \\
\hline & No & 256 & 88.3 \\
\hline \multirow[t]{2}{*}{ UTI within the past 12 month } & Yes & 40 & 14.1 \\
\hline & No & 244 & 85.9 \\
\hline \multirow[t]{3}{*}{ Paternal education } & No education & 78 & 27.5 \\
\hline & Primary & 87 & 30.6 \\
\hline & Secondary and above & 119 & 41.9 \\
\hline \multirow[t]{3}{*}{ Maternal education } & No education & 109 & 38.4 \\
\hline & Primary & 87 & 30.6 \\
\hline & Secondary and above & 88 & 31.0 \\
\hline \multirow[t]{4}{*}{ Paternal occupation } & Employed & 125 & 44.0 \\
\hline & Merchant & 46 & 16.2 \\
\hline & Farmer & 82 & 28.9 \\
\hline & Daily laborers & 31 & 10.9 \\
\hline \multirow[t]{3}{*}{ Maternal occupation } & House wife & 173 & 60.9 \\
\hline & Employed & 61 & 21.5 \\
\hline & Merchant & 50 & 17.6 \\
\hline
\end{tabular}

Table 2: Frequency of ESBL producer and Non-ESBL producer Enterobacteriaceae isolated from children suspected of UTI at HUCSH from Feb 1/ 2018-July 30, Hawassa, Ethiopia. 


\begin{tabular}{|c|c|c|c|c|c|c|c|c|c|}
\hline & $\begin{array}{l}K . \\
\text { pneumoniae } \\
\text { No (\%) }\end{array}$ & $\begin{array}{l}\text { E. coli } \\
\text { No (\%) }\end{array}$ & $\begin{array}{l}K . \\
\text { oxytoca } \\
\text { No (\%) }\end{array}$ & $\begin{array}{l}\text { K. } \\
\text { ozaenae } \\
\text { No (\%) }\end{array}$ & $\begin{array}{l}E . \\
\text { cloacae } \\
\text { No (\%) }\end{array}$ & $\begin{array}{l}P . \\
\text { mirabilis } \\
\text { No (\%) }\end{array}$ & $\begin{array}{l}\text { C. } \\
\text { diversus } \\
\text { No (\%) }\end{array}$ & $\begin{array}{l}\text { Providencia spp. No } \\
\text { (\%) }\end{array}$ & Total \\
\hline BL-Producer & $14(70)$ & $\begin{array}{l}12 \\
(37.5)\end{array}$ & $3(50)$ & 1 (33.3) & $0(0.0)$ & $0(0.0)$ & $0(0.0)$ & $0(0.0)$ & $\begin{array}{l}30 \\
(41.7)\end{array}$ \\
\hline $\begin{array}{l}\text { n-ESBL } \\
\text { ducer }\end{array}$ & $6(30)$ & $\begin{array}{l}20 \\
(62.5)\end{array}$ & $3(50)$ & $2(66.7)$ & $2(100)$ & $2(100)$ & $3(100)$ & $4(100)$ & $\begin{array}{l}42 \\
(58.3)\end{array}$ \\
\hline $\mathrm{al}$ & $20(100)$ & $\begin{array}{l}32 \\
(100)\end{array}$ & $6(100)$ & $3(100)$ & $2(100)$ & $2(100)$ & $3(100)$ & $4(100)$ & $72(100)$ \\
\hline
\end{tabular}

Table 3: Bivariate and multivariable analysis of independent variables against ESBL production status among UTI suspected children (<15 years) at HUCSH from Feb 1/ 2018-July 30/2018, Hawassa, Ethiopia.

\begin{tabular}{|c|c|c|c|c|c|c|}
\hline \multicolumn{2}{|l|}{ riable } & \multirow{2}{*}{\begin{tabular}{|l}
$\begin{array}{l}\text { ESBL } \\
\text { producer }\end{array}$ \\
11
\end{tabular}} & \multirow{2}{*}{$\begin{array}{l}\begin{array}{l}\text { ESBL non- } \\
\text { producer }\end{array} \\
28\end{array}$} & \multirow{2}{*}{$\begin{array}{l}\text { COR (95\% CI) } \\
1\end{array}$} & \multirow{2}{*}{$\begin{array}{l}\mathrm{AOR}(95 \% \mathrm{CI}) \\
1\end{array}$} & \multirow[t]{2}{*}{$\begin{array}{l}\text { P. } \\
\text { value }\end{array}$} \\
\hline \multirow[t]{3}{*}{$\mathrm{ye}$} & $0-4$ & & & & & \\
\hline & $5-9$ & 7 & 8 & $\begin{array}{l}0.449(0.131- \\
1.538)\end{array}$ & $\begin{array}{l}0.506(0.078- \\
3.261)\end{array}$ & 0.473 \\
\hline & $10-14$ & 12 & 6 & $\begin{array}{l}0.196(0.059- \\
0.654)\end{array}$ & $\begin{array}{l}0.183(0.029- \\
1.157)\end{array}$ & 0.071 \\
\hline \multirow[t]{2}{*}{ ice of residence } & Urban & 22 & 20 & 1 & 1 & \multirow[t]{2}{*}{0.142} \\
\hline & Rural & 8 & 22 & $\begin{array}{l}3.025(1.101- \\
8.311)\end{array}$ & $\begin{array}{l}3.900(0.634-13- \\
984)\end{array}$ & \\
\hline \multirow[t]{2}{*}{ tient type } & Outpatient & 16 & 13 & 1 & 1 & \multirow[t]{2}{*}{0.301} \\
\hline & Inpatient & 14 & 29 & $\begin{array}{l}2.549(0.966- \\
6.731)\end{array}$ & $\begin{array}{l}2.546(0.433-14- \\
958)\end{array}$ & \\
\hline \multirow{2}{*}{$\begin{array}{l}\text { I within the past } 12 \\
\text { inth }\end{array}$} & No & 20 & 34 & 1 & 1 & \multirow[t]{2}{*}{$0.012^{*}$} \\
\hline & Yes & 10 & 8 & $\begin{array}{l}0.471(0.160- \\
1.388)\end{array}$ & $\begin{array}{l}0.076(0.010- \\
0.569)\end{array}$ & \\
\hline \multirow{2}{*}{$\begin{array}{l}\text { rgery past } 6 \\
\text { inth }\end{array}$} & Yes & 6 & 7 & 1 & \multirow[t]{2}{*}{ NA } & \\
\hline & No & 24 & 35 & $\begin{array}{l}0.800(0.239- \\
2.677)\end{array}$ & & \\
\hline \multirow[t]{4}{*}{ ternal occupation } & Employee & 11 & 16 & 1 & 1 & \\
\hline & Merchant & 8 & 4 & $\begin{array}{l}0.344(0.083- \\
1.429)\end{array}$ & $\begin{array}{l}0.136(0.14- \\
1.324)\end{array}$ & 0.086 \\
\hline & Farmer & 10 & 15 & $\begin{array}{l}1.031(0.340- \\
3.126)\end{array}$ & $\begin{array}{l}0.399(0.027- \\
5.815)\end{array}$ & 0.502 \\
\hline & Daily laborers & 1 & 7 & $\begin{array}{l}4.812(0.517-14- \\
822)\end{array}$ & $\begin{array}{l}2.669(0.149- \\
9.061)\end{array}$ & 0.328 \\
\hline \multirow[t]{3}{*}{ aternal occupation } & House wife & 19 & 25 & 1 & \multirow[t]{3}{*}{ NA } & \\
\hline & Employee & 5 & 6 & $\begin{array}{l}0.912(0.242- \\
3.442)\end{array}$ & & \\
\hline & Merchant & 6 & 11 & $\begin{array}{l}1.393(0.437 \\
4.444)\end{array}$ & & \\
\hline \multirow[t]{3}{*}{ ternal education } & No education & 8 & 18 & 1 & 1 & \\
\hline & Primary & 10 & 12 & $\begin{array}{l}0.533(0.164- \\
1.740)\end{array}$ & $\begin{array}{l}0.294(0.021- \\
4.080)\end{array}$ & 0.362 \\
\hline & $\begin{array}{l}\text { Secondary and } \\
\text { above }\end{array}$ & 12 & 12 & $\begin{array}{l}0.444(0.140- \\
1.411)\end{array}$ & $\begin{array}{l}0.309(0.012- \\
7.908)\end{array}$ & 0.478 \\
\hline \multirow[t]{3}{*}{ iternal education } & No education & 10 & 20 & 1 & 1 & \\
\hline & Primary & 12 & 10 & $\begin{array}{l}0.417(0.134- \\
1.292)\end{array}$ & $\begin{array}{l}0.078(0.003- \\
2.384)\end{array}$ & 0.144 \\
\hline & $\begin{array}{l}\text { Secondary and } \\
\text { above }\end{array}$ & 8 & 12 & $\begin{array}{l}0.750(0.232- \\
2.424)\end{array}$ & $\begin{array}{l}0.843(0.020- \\
14.961)\end{array}$ & 0.929 \\
\hline \multirow[t]{3}{*}{ mily wealth index } & Poor & 4 & 10 & 1 & 1 & \\
\hline & Medium & 23 & 19 & $\begin{array}{l}0.330(0.089- \\
1.224)\end{array}$ & $\begin{array}{l}0.029(0.003- \\
0.265)\end{array}$ & $0.002^{*}$ \\
\hline & Rich & 3 & 13 & $\begin{array}{l}1.733(0.314- \\
9.573)\end{array}$ & $\begin{array}{l}2.984(0.144- \\
12.696)\end{array}$ & 0.479 \\
\hline
\end{tabular}

COR: Crude odds ratio; AOR: Adjusted odds ratio, * P value $<0.05$, NA: not applicable, that is the variable did not meet criterion ( $\mathrm{P}$ value $<0.25$ ) to be included in multivariate analysis. 
Table 4: Antibacterial resistance levels of Enterobacteriaceae isolated from children (<15 years) suspected of UTI in pediatric department at HUCSH from Feb 1/ 2018-July 30, Hawassa, Ethiopia.

\begin{tabular}{|c|c|c|c|c|c|c|c|c|c|c|c|c|c|}
\hline \multirow[t]{2}{*}{$\begin{array}{l}\text { Organism } \\
\text { Isolated }\end{array}$} & \multirow[t]{2}{*}{ No } & \multicolumn{12}{|c|}{ Antibacterial resistance level of Enterobacteriaceae isolates, $n$ (\%) } \\
\hline & & AMC & AMP & CIP & GEN & STX & NIF & CTR & FOX & TET & NOR & CXT & MEM \\
\hline $\begin{array}{l}\bar{K} \text { K. } \\
\text { pneumoniae }\end{array}$ & 20 & $\begin{array}{l}19 \\
(95)\end{array}$ & $\begin{array}{l}19 \\
(95)\end{array}$ & $\begin{array}{l}7 \\
(35)\end{array}$ & $\begin{array}{l}17 \\
(85)\end{array}$ & $\begin{array}{l}17 \\
(85)\end{array}$ & $\begin{array}{l}7 \\
(35)\end{array}$ & $\begin{array}{l}17 \\
(85)\end{array}$ & $\begin{array}{l}11 \\
(55)\end{array}$ & $\begin{array}{l}17 \\
(85)\end{array}$ & $\begin{array}{l}8 \\
(40)\end{array}$ & $\begin{array}{l}15 \\
(75)\end{array}$ & $\begin{array}{l}11 \\
(55)\end{array}$ \\
\hline E. coli & 32 & $\begin{array}{l}30 \\
(93.8)\end{array}$ & $\begin{array}{l}29 \\
(90.6)\end{array}$ & $\begin{array}{l}20 \\
(62.5)\end{array}$ & $\begin{array}{l}28 \\
(87.5)\end{array}$ & $\begin{array}{l}29 \\
(90.6)\end{array}$ & $\begin{array}{l}5 \\
(15.6)\end{array}$ & $\begin{array}{l}22 \\
(68.8)\end{array}$ & $\begin{array}{l}22 \\
(68.8)\end{array}$ & $\begin{array}{l}24 \\
(75)\end{array}$ & $\begin{array}{l}19 \\
(59.4)\end{array}$ & $\begin{array}{l}20 \\
(62.5)\end{array}$ & $\begin{array}{l}6 \\
(18.8)\end{array}$ \\
\hline K. ozaenae & 3 & $\begin{array}{l}3 \\
(100)\end{array}$ & $\begin{array}{l}3 \\
(100)\end{array}$ & $\left.\begin{array}{ll}0 \\
0\end{array}\right) \quad($ & $\begin{array}{l}3 \\
(100)\end{array}$ & ${ }^{2}(66.7)$ & $\begin{array}{l}1 \\
(33.3)\end{array}$ & $\begin{array}{l}3 \\
(100)\end{array}$ & $\begin{array}{l}1 \\
(33.3)\end{array}$ & $\begin{array}{l}3 \\
(100)\end{array}$ & $\begin{array}{l}0 \\
0)\end{array}$ & ${ }^{2}(66.7)$ & $\begin{array}{l}2 \\
(66.7)\end{array}$ \\
\hline K. oxytoca & 6 & $\begin{array}{l}6 \\
(100)\end{array}$ & $\begin{array}{l}6 \\
(100)\end{array}$ & $\begin{array}{l}4 \\
(66.7)\end{array}$ & $\begin{array}{l}5 \\
(83.3)\end{array}$ & $\begin{array}{l}6 \\
(100)\end{array}$ & $\begin{array}{l}4 \\
(66.7)\end{array}$ & $\begin{array}{l}5 \\
(83.3)\end{array}$ & $\begin{array}{l}2 \\
(33.3)\end{array}$ & 4 & $\begin{array}{l}2 \\
(33.3)\end{array}$ & 5 & $\begin{array}{l}4 \\
(66.7)\end{array}$ \\
\hline $\begin{array}{l}\text { Enterobacter } \\
\text { cloacae }\end{array}$ & 2 & $\begin{array}{l}2 \\
(100)\end{array}$ & $\begin{array}{l}2 \\
(100)\end{array}$ & $\begin{array}{l}1 \\
(50)\end{array}$ & $\begin{array}{l}2 \\
(100)\end{array}$ & ${ }^{2}(100)$ & 0 & 1 & $\begin{array}{l}1 \\
(50)\end{array}$ & $\begin{array}{l}1 \\
(50)\end{array}$ & $\left.\begin{array}{l}0 \\
0\end{array}\right)$ & $\begin{array}{l}1 \\
(50)\end{array}$ & $\left.\begin{array}{ll}0 \\
0\end{array}\right)$ \\
\hline P. mirabilis & 2 & $\begin{array}{l}2 \\
(100)\end{array}$ & 2 & $\begin{array}{l}0 \\
0)\end{array}$ & 2 & 2 & $\begin{array}{ll}0 & (0 \\
) & \end{array}$ & $\left.\begin{array}{l}0 \\
0\end{array}\right)($ & $\begin{array}{l}2 \\
(100)\end{array}$ & $\begin{array}{l}1 \\
(50)\end{array}$ & $\begin{array}{l}1 \\
(50)\end{array}$ & $\left.\begin{array}{l}0 \\
0\end{array}\right)($ & $\left.\begin{array}{l}0 \\
0\end{array}\right)$ \\
\hline $\begin{array}{l}\text { Citrobacter } \\
\text { diversus }\end{array}$ & 3 & $\begin{array}{l}3 \\
(100)\end{array}$ & $\begin{array}{l}3 \\
(100)\end{array}$ & 1 & 2 & $\begin{array}{l}2 \\
(66.7)\end{array}$ & $\begin{array}{l}0 \\
(0)\end{array}$ & $\begin{array}{l}2 \\
(66.7)\end{array}$ & 2 & $\begin{array}{l}2 \\
(66.7)\end{array}$ & $\begin{array}{l}2 \\
(66.7)\end{array}$ & ${ }^{2}(66.7)$ & $\begin{array}{l}2 \\
(66.7\end{array}$ \\
\hline $\begin{array}{l}\text { Providencia } \\
\text { spp. }\end{array}$ & 4 & $\begin{array}{l}4 \\
(100)\end{array}$ & $\begin{array}{l}4 \\
(100)\end{array}$ & $\begin{array}{l}1 \\
(25)\end{array}$ & $\begin{array}{l}3 \text { (75) } \\
\end{array}$ & $\begin{array}{ll}2 & \\
& \end{array}$ & $\begin{array}{l}2(50) \\
\end{array}$ & $\begin{array}{l}4 \\
(100)\end{array}$ & $\begin{array}{l}2 \\
(50)\end{array}$ & $\begin{array}{l}2 \\
(50)\end{array}$ & $\begin{array}{ll}1 & \\
& \end{array}$ & $\begin{array}{ll}3 & \\
& (75)\end{array}$ & $\begin{array}{l}4 \\
(100)\end{array}$ \\
\hline Total & 72 & $\begin{array}{l}69 \\
(95.8)\end{array}$ & $\begin{array}{l}68 \\
(94.4)\end{array}$ & $\begin{array}{l}34 \\
(47.2)\end{array}$ & $\begin{array}{l}62 \\
(86.1)\end{array}$ & $\begin{array}{l}62 \\
(86.1)\end{array}$ & $\begin{array}{l}19 \\
(26.4)\end{array}$ & $\begin{array}{l}54 \\
(75) \\
\end{array}$ & $\begin{array}{l}43 \\
(59.7)\end{array}$ & $\begin{array}{l}54 \\
(75) \\
\end{array}$ & $\begin{array}{l}33 \\
(45.8)\end{array}$ & $\begin{array}{l}49 \\
(68) \\
\end{array}$ & $\begin{array}{c}29 \\
(40.3)\end{array}$ \\
\hline
\end{tabular}

Abbreviations: AMC-Amoxacillin/clavulanate, AMP-Ampicillin, CIP-Ciprofloxacin, GN-Gentamicin, STX- trimethoprimsulfamethoxazole, NIF-Nitrofurantoin, CTR -Ceftriaxone, FOX-Cefoxitin, TET-Tetracycline, NOR- Norfloxacin, CXTCefotaxime, MEM-Meropenem.

Table 5: Multidrug resistance level of Enterobacteriaceae isolated from children (<15 years) suspected of UTI in pediatric department at HUCSH from Feb 1/ 2018-July 30, Hawassa, Ethiopia.

\begin{tabular}{|c|c|c|c|c|c|c|c|c|c|}
\hline & \multicolumn{8}{|c|}{ Level of antibiotics resistance ((number (\%)) } & \multirow{2}{*}{$\begin{array}{l}\text { Total MDR-E } \\
(\geq \mathrm{R} 3)\end{array}$} \\
\hline Isolates (number) & R0 & R1 & $\mathrm{R} 2$ & R3 & R4 & $\mathrm{R} 5$ & R6 & R7 & \\
\hline E. coli (32) & $0(0.0)$ & $1(3.1)$ & $2(6.3)$ & $8(25)$ & $7(21.9)$ & $7(21.9)$ & $4(12.5)$ & $3(9.4)$ & $29(90.6)$ \\
\hline K. pneumonea (20) & $0(0.0)$ & $1(5.0)$ & $2(10.0)$ & $8(40.0)$ & $4(20.0)$ & $3(15.0)$ & $1(5.0)$ & $1(5.0)$ & $17(85.0)$ \\
\hline K. ozaenae (3) & $0(0.0)$ & $0(0.0)$ & $0(0.0)$ & $2(66.7)$ & $0(0.0)$ & $0(0.0)$ & $1(33.3)$ & $0(0.0)$ & $3(100)$ \\
\hline K. oxytoca (6) & $0(0.0)$ & $1(16.7)$ & $1(16.7)$ & $1(16.7)$ & $0(0.0)$ & $2(33.3)$ & $0(0.0)$ & $1(16.7)$ & $4(66.7)$ \\
\hline $\begin{array}{l}\text { Enterobacter } \\
\text { cloacae(2) }\end{array}$ & $0(0.0)$ & $0(0.0)$ & $0(0.0)$ & $1(50.0)$ & $1(50.0)$ & $0(0.0)$ & $0(0.0)$ & $0(0.0)$ & $2(100)$ \\
\hline $\begin{array}{l}\text { Citrobacter } \\
\text { diversus (3) }\end{array}$ & $0(0.0)$ & $0(0.0)$ & $0(0.0)$ & $0(0.0)$ & $1(33.3)$ & $0(0.0)$ & $1(33.3)$ & $0(0.0)$ & $2(66.7)$ \\
\hline P. mirabilis (2) & $0(0.0)$ & $0(0.0)$ & $0(0.0)$ & $0(0.0)$ & $1(50.0)$ & $1(50.0)$ & $0(0.0)$ & $0(0.0)$ & $2(100)$ \\
\hline Providencia spp. (4) & $0(0.0)$ & $1(25.0)$ & $0(0.0)$ & $1(25.00$ & $0(0.0)$ & $2(50.0)$ & $0(0.0)$ & $0(0.0)$ & $3(75.0)$ \\
\hline Total (72) & & & & & & & & & $62(86.1)$ \\
\hline
\end{tabular}


Table 6: Antibacterial resistance levels of ESBL-producing and Non-ESBL producing Enterobacteriaceae among UTI suspected children (<15 years) at HUCSH from Feb 1/ 2018-July 30, Hawassa, Ethiopia.

\begin{tabular}{|l|l|l|l|l|}
\hline $\mathbf{S} / \mathbf{N}$ & Drugs & $\begin{array}{l}\text { ESBL producer (30) } \mathbf{n}(\% \\
\text { of NS*) }\end{array}$ & $\begin{array}{l}\text { ESBL non-producer (42) } \\
\text { n(\% of NS) }\end{array}$ & $\begin{array}{l}\text { Total Enterobacteriaceae } \\
\text { n(\% of NS) }\end{array}$ \\
\hline 1 & $\begin{array}{l}\text { Amoxacillin/Clavulanic } \\
\text { acid }\end{array}$ & $29(96.7)$ & $40(95.2)$ & $69(95.8)$ \\
\hline 2 & Ampicillin & $29(96.7)$ & $39(92.9)$ & $68(94.4)$ \\
\hline 3 & Ciprofloxacin & $17(56.7)$ & $17(40.5)$ & $34(47.2)$ \\
\hline 4 & Gentamycin & $29(96.7)$ & $33(78.6)$ & $62(86.1)$ \\
\hline 5 & Co-trimoxazole & $29(96.7)$ & $33(78.6)$ & $62(86.1)$ \\
\hline 6 & Nitrofurantoin & $12(40)$ & $7(16.7)$ & $19(26.4)$ \\
\hline 7 & Ceftriaxone & $27(90)$ & $27(64.3)$ & $54(75)$ \\
\hline 8 & Cefoxitin & $23(76.7)$ & $20(47.6)$ & $43(59.7)$ \\
\hline 9 & Tetracycline & $26(86.7)$ & $28(66.7)$ & $54(75)$ \\
\hline 10 & Norfloxacin & $20(66.7)$ & $13(30.9)$ & $33(45.8)$ \\
\hline 11 & Cefotaxime & $29(96.7)$ & $20(47.6)$ & $29(68.1)$ \\
\hline 12 & Meropenem & $17(56.7)$ & $12(28.6)$ & $29.3)$ \\
\hline
\end{tabular}

NS*: Non-susceptible

\section{Figures}

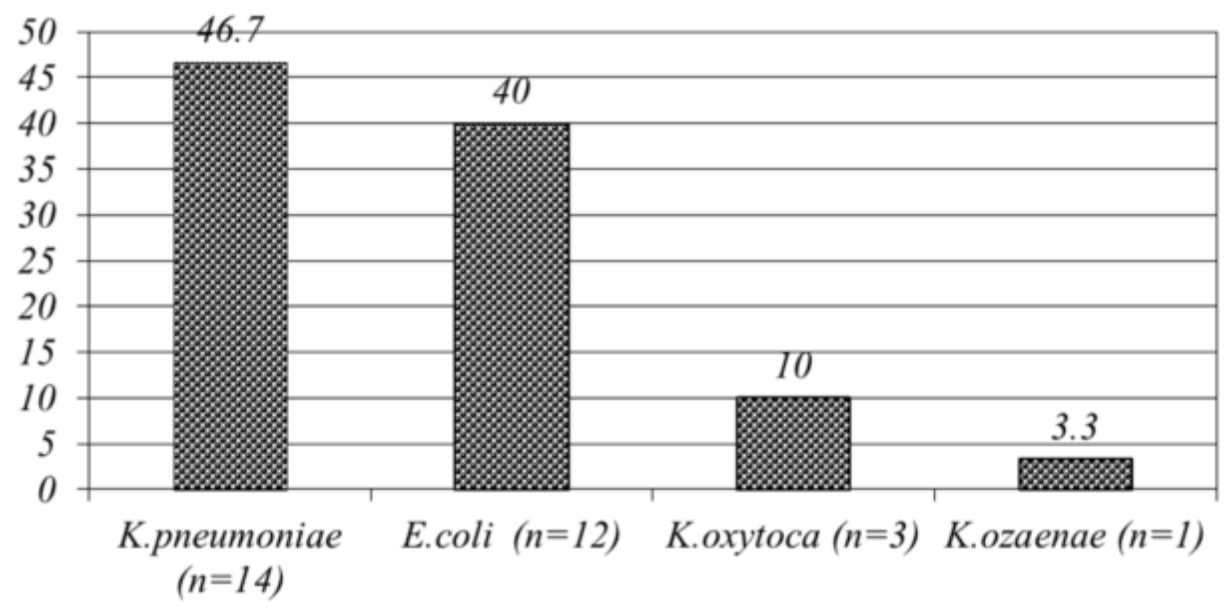

\section{Figure 1}

The graph displays percent of ESBL production of individual bacteria out of the total ESBL producing Enterobacteriaceae isolates $(n=30)$. 